\title{
Healing dynamics of porcine pancreatic parenchyma after radiofrequency ablation - in vivo experimental pilot study
}

\author{
Jan Hlavsa ${ }^{1}$, Vladimír Procházka ${ }^{1}$, Michal $\mathrm{Crha}^{2}$, Iva Svobodová3 ${ }^{\text {, Tomáš Andrašina }}{ }^{4}$, \\ Petr Raušer ${ }^{5}$, Lucie Urbanovás, Tomáš Pavlík ${ }^{6}$, Jana Lorenzová ${ }^{5}$, Alois Nečas ${ }^{2}$, \\ Zdeněk Kala ${ }^{1}$
}

'Masaryk University Brno, University Hospital Brno Bohunice and Faculty of Medicine, Department of Surgery, Brno, Czech Republic

${ }^{2}$ University of Veterinary and Pharmaceutical Sciences Brno, CEITEC - Central European Institute of Technology, Brno, Czech Republic

${ }^{3}$ Masaryk University Brno, Saint Anne's University Hospital Brno and Faculty of Medicine, Department of Pathology, ${ }^{4}$ University Hospital Brno Bohunice and Faculty of Medicine, Department of Radiology, Brno, Czech Republic

${ }^{5}$ University of Veterinary and Pharmaceutical Sciences Brno, Faculty of Veterinary Medicine, Small Animal Clinic, Department of Surgery and Orthopedics, Brno, Czech Republic ${ }^{6}$ Masaryk University Brno, Faculty of Medicine, Institute of Biostatistics and Analysis, Brno, Czech Republic

Received February 29, 2012

Accepted July 16, 2012

\begin{abstract}
Radiofrequency ablation is a tumour destruction method, widely used in human as well veterinary medicine. Recently, it has been applied to pancreatic disorder treatment. However, little is known about healing of the pancreatic parenchyma after radiofrequency ablation as it is important for the prevention of complications and treatment strategy. The aim of this experimental in vivo study on pigs was to evaluate the pancreatic parenchyma healing dynamics after damage by radiofrequency ablation. Radiofrequency ablations of the duodenal lobe of the pancreas were performed on 8 cross-bred laboratory pigs. They were euthanized in pairs at seven, fourteen, forty and eighty days after the procedure. Histological and cytological changes of the ablated zone were evaluated after autopsy. It was proved that pancreatic necrosis after radiofrequency ablation heals by means of fibrotic scar. There was no sign of exocrine and endocrine regeneration, respectively, during 80 days after the procedure. This is the first study verifying that the healing process of an ablation zone in the pancreatic parenchyma after radiofrequency ablation is similar to healing in the liver, lung, heart and other parenchymal organs.
\end{abstract}

Thermoablation, healing, necrosis, animal model, pig

Radiofrequency ablation (RFA) was known as a tumour destruction method, widely used in both human and veterinary medicine (Pollard et al. 2001; Spiliotis et al. 2007; Hlavsa et al. 2008). One of the target organs for this method is also the pancreas. Since 1990s there have been more than twenty studies trying to specify which pancreatic disorder is an "ideal" indication for RFA. Some of them described appropriate ablation protocols specific to pancreatic tissue (Date et al. 2005). Others focused on the clinical impact of RFA at pancreatic cancer or pancreatic neuroendocrine tumours (Tang et al. 2008; Girelli et al. 2010; Zou et al. 2010; Hlavsa et al. 2011). Based on the experimental studies, several authors advised on how to prevent RFA associated complications (Date et al. 2005; Girelli et al. 2010; Crha et al. 2012). In this context, RFA could become a therapeutic method of choice for pancreatic disorders in the future. The questions that have not been answered yet concern the healing dynamics in the ablated areas of pancreatic tissue which is important for the

Address for correspondence:

MUDr. Vladimír Procházka, PhD.

Department of Surgery

Faculty of Medicine

Masaryk University Brno

Jihlavská 20, 62500 Brno, Czech Republic 
understanding of RFA effects on the pancreatic tissue at the cellular level. The aim of this study was to describe the healing and regeneration processes of pancreatic tissue after radiofrequency ablation in laboratory pigs.

\section{Materials and Methods}

We performed an experimental in vivo pilot study on a group of 8 laboratory cross-bred piglets $(50 \%$ Duroc, $25 \%$ Pietrain, $25 \%$ Landrace, 4 months of age, weighing $35-40 \mathrm{~kg}$ ). The study was approved by the Animal Ethics Committee of the University of Veterinary and Pharmaceutical Sciences Brno, Czech Republic. The pigs were housed in stone hutches under controlled environmental conditions $\left(20\right.$ to $22{ }^{\circ} \mathrm{C}$ room temperature, $50 \%$ to $60 \%$ relative humidity, $12 \mathrm{~h}$ light/12 h dark cycle). The animals were assigned to four groups with two pigs per group. Each animal underwent a median laparotomy and an intraoperative radiofrequency ablation of the pancreas. The whole procedure was carried out under general anaesthesia. All pigs were sedated by intramuscular administration of tiletamine-zolazepam ( $2 \mathrm{mg} \cdot \mathrm{kg}^{-1}$, Zoletil 100, Virbac, France), xylazine $\left(0.5 \mathrm{mg} \cdot \mathrm{kg}^{-1}, \mathrm{Xylazin}_{2} \%\right.$, Riemser, Germany) and ketamine ( $2 \mathrm{mg} \cdot \mathrm{kg}^{-1}$, Narketan, Vetoquinol, France) mixture. All substances were administered together in a single syringe. Anaesthesia was induced by intravenous administration of propofol $\left(1-2 \mathrm{mg} \cdot \mathrm{kg}^{-1}\right.$, Propofol 1\%, Fresenius, Austria) and maintained by continuous intravenous administration of propofol (0.1$\left.0.3 \mathrm{mg} \cdot \mathrm{kg}^{-1} \cdot \mathrm{min}^{-1}\right)$. All animals were intubated and artificially ventilated. A self-adhesive gelled grounding pad was placed on a shaved surface on a hind limb of the animal. The midline laparotomy was performed under aseptic conditions. Then the duodenal pancreatic lobe was approached and RFA ablation was performed. A RFA generator (RITA 1500X, Angiodynamics, Manchester GA, USA) with a $2 \mathrm{~cm}$ umbrella RFA electrode (StarBurst XL Electrode, length $15 \mathrm{~cm}$; O.D $14 \mathrm{Ga} / 6.4 \mathrm{~F})$ was used for all the ablations using ablation protocol $\left(60{ }^{\circ} \mathrm{C}\right.$ in the ablated area for $5 \mathrm{~min}$ ). The mean diameter of the ablated area was $2 \mathrm{~cm}$. Finally, the abdominal wall was closed in three layers. The animals of different groups were euthanized at 7, 14, 40 and 80 days after surgery, respectively. In each pig, the duodenal pancreatic lobe was excised with the adjacent duodenum. All specimens were fixed in formalin and embedded in paraffin. A histopathology was performed in haematoxylin-eosin or periodic-acid-shiff stained slides and involved the evaluation of histological description of the pancreatic necrosis and the transient area (TA) between necrosis and healthy pancreatic parenchyma. A synaptophysin stain was also used to verify the presence of neuroendocrine tissue. All specimens were evaluated by one experienced pathologist. The sample of healthy porcine pancreas from a commercial abattoir was obtained as a control (Plate IV, Figs 1a, 1b).

\section{Results}

The postoperative course was uncomplicated in 7 cases. One pig died due to acute necrotizing pancreatitis 14 days after the procedure and was excluded from the study. The remaining seven pigs were euthanized and histologically examined according to the plan.

Seven days after the radiofrequency ablation, the necrosis of exocrine and even endocrine pancreas was already visible in the central ablation zone. The necrosis manifested as an amorphous eosinophil (in haematoxylin-eosin stain) matter with disintegrated endocrine islets, acinar vanish and slightly distorted residual ducts. The reparative changes consisted of strong vascularized granular tissue with capillaries, fibroblasts and inflammatory cells (neutrophils, lymphocytes); macrophages phagocytosing necrotic tissue were visible in the necrosis periphery in haematoxylin-eosin stain (Plate IV, Figs 2a,b,c).

The histological findings were similar even 14 days after the RFA. Regressive changes with no acini and residual pancreatic ducts were detected in the central ablation zone. This was surrounded by reparative reaction (transient zone) consisting of granular, oedematous, strongly vascularized tissue with fibroblasts and inflammatory infiltration (neutrophils, lymphocytes, macrophages) (Plate IV, Figs 3a,b,c). Contrary to the 7 day group, there were no signs of even residual endocrine islets 14 days after the RFA (Plate IV, Fig. 3c).

Forty days after the RFA, the transient zone (TZ) between central ablation zone and pancreatic parenchyma became more fibrous (Plate V, Figs 4a,b). Hyalinization was proved in the periphery of $\mathrm{TZ}$, close to the pancreatic parenchyma (Plate $\mathrm{V}$, Fig. 4b). As with the previous groups, some residual pancreatic ducts were detected (Plate V, Figs 4a,b,c). No endocrine islets were visualized in the ablated zone and TA, respectively (Plate V, Fig. 4c). Nerve fibres were proved in TZ in this group (Plate V, Fig. 4a) suggesting that they need not to be destroyed by slightly elevated temperatures 
(Note: It was not possible to measure the temperature in TZ in our study, but regarding physical principles, the temperature in TA is supposed to be lower than temperature in the ablated zone, i.e. lower than $60{ }^{\circ} \mathrm{C}$ ).

Eighty days after the RFA, the process of fibrotisation was continuing. A cross-section histology showed inflammatory-reparative changes consisting of granular tissue maturing to fibrous tissue in the ablated zone and TZ, respectively. Residual pancreatic ducts were found in TZ in this group (Plate VI, Figs 5a,b,c). Synaptophysin stain did not prove any signs of residual endocrine cells or their regeneration (Plate V, Fig. 5c).

\section{Discussion}

There are many clinical experimental studies describing local changes after RFA at cellular and subcellular levels both in human and veterinary medicine. From this viewpoint, the most explored organs have been the liver, lung and heart. It has been proved by liver models that tissue injury following thermal ablation occurs in two distinct phases (Vanag as et al. 2010). The initial phase is direct injury. The second phase is indirect or progressive injury, which follows the cessation of the focal hyperthermic stimulus. Direct thermal injury involves all the reactions in the tissue at cellular and subcellular levels. The tissue effects depend on the energy, duration of the thermal injury, thermal sensitivity of cells, and the characteristics of the heat removal mechanisms, which vary in different organs and tissues (Barauskas et al. 2007a). The main mechanism of tissue injury involves the inactivation of vital enzymes. Temperatures between $100{ }^{\circ} \mathrm{C}$ and $300{ }^{\circ} \mathrm{C}$ induce vaporization of tissue water, carbonization, and smoke generation. Carbonization limits the extent of tissue damage by creating a heat trap caused by impedance increase. In clinical setting, the heat transfer is improved by tissue infiltration with saline, which prevents tissue carbonization and safeguards against excessive increases in impedance. Coagulation of tissue is induced at temperatures between $60{ }^{\circ} \mathrm{C}$ and $100{ }^{\circ} \mathrm{C}$ and manifests as an irreversible damage to mitochondrial and cytosolic enzymes of the cells. The temperature decreases away from the active probe and is reflected by different morphological changes in the affected tissues (Barauskas et al. 2007b).

These changes are morphologically described as four zones: 1 - application, 2 - central, 3 transition and 4 - reference tissue zone. The application zone is located immediately next to the thermal electrode and is characterized by irreversible damage (carbonization). Necrotic tissue with damaged structure of hepatic cells was observed in the central zone (the ablation zone in our study). The transition zone, surrounding the central zone, is morphologically described as haemorrhagic area, containing apparently undamaged liver cells with signs of tissue infiltration with blood cells. In this zone, cells are eosinophilic with condensed chromatin; however, intercellular connections are maintained. The reference zone referrers to the normal tissue surrounding the transition zone (Vanagas et al. 2009). The most complicated processes of thermal tissue damage are observed in the transition zone. This zone contains cells in the earliest stages of cellular death, demonstrating loss of enzymatic activity. The direct effect of heat stimulus at the subcellular level results in impaired membrane and mitochondrial function, destruction of nucleic acids and cytoskeleton. Cell viability accurately correlates with ultrastructural changes in the mitochondria. Formation of intramitochondrial dense granules, vesicularization of the crista, intracristal space swelling, and myelin degeneration are observed. These changes promote proton leakage across the inner mitochondrial membrane, and impair oxidative phosphorylation (Willis et al. 2000).

In our study, we have found some histologically different zones after RFA in porcine pancreas: 1) ablated zone, 2) transient zone and 3) reference zone. As in liver studies, the ablated zone in our study consisted of amorphous eosinophilic tissue with 
disintegrated pancreatic parenchyma cells. Similarly, as in the study by Coad et al. (2003) describing RFA of human hepatocellular carcinoma, the ablated zone was covered with macrophages (belonging to the transient zone) 7 days after RFA (Fig. 2b). There were no major differences in the transient zone (Coad et al. 2003). We have proved strong vascularized granular tissue with capillaries, fibroblasts, inflammatory cells (neutrophils, lymphocytes) and macrophages phagocytizing necrotic tissue in TZ. We have proved that the healing of porcine pancreas is similar to liver, lung, and heart studies (Coad et al. 2003; Crocetti et al. 2010; Arfelli et al. 2011; Lesser et al. 2011). This is characterized by progressive fibrotisation of the ablated and even the transient zone. We have proved that pancreatic necrosis after radiofrequency ablation heals by fibrotic scar with no signs of exocrine and endocrine regeneration. During the healing process there is a ring of active inflammation surrounding the ablated zone. This so called transient zone was proved to be full of fibroblasts, inflammatory cells and capillaries. In the future, the hyperaemic ring could be the target of e.g. antitumour drugs both in human and veterinary medicine.

\section{Acknowledgements}

This work was supported by the grants agency Ministry of Health Czech Republic (IGA MZ ČR) (Projects No. NS10239-3/2009 and NS10419-3/2009) and by the project "CEITEC - Central European Institute of Technology" (CZ.1.05/1.1.00/02.0068) from European Regional Development Fund.

\section{References}

Arfelli E, de Araujo S, Okada M, Nascimento T, dos Santos LF, Franco M, de Paola AA, Fenelon G 2011: Impact of corticosteroids on late growth of radiofrequency lesions in infant pigs: histopathological and electroanatomical finding. Europace 13: 121-128

Barauskas R, Gulbinas A, Barauskas G 2007a: Finite element modeling and experimental investigation of infiltration of sodium chloride solution into nonviable liver tissue. Medicina (Kaunas) 43: 399-411

Barauskas R, Gulbinas A, Barauskas G 2007b: Investigation of radiofrequency ablation process in liver tissue by finite element modeling and experiment. Medicina (Kaunas) 43: 310-325

Coad J, Kosari K, Humar A, Sielaff TD 2003: Radiofrequency ablation causes 'thermal fixation' of hepatocellular carcinoma: a post-liver transplant histopathologic study. Clin Transplant 17: 377-384

Crha M, Hlavsa J, Procházka V, Andrašina T, Svobodová I, Urbanová L, Pavlík T, Raušer P, Lorenzová J, Kala Z, Nečas A 2012: Radiofrequency ablation of pancreas and optimal cooling of peripancreatic tissue in an ex-vivo porcine model. Acta Vet Brno 80: 407-413

Crocetti L, Bozzi E, Faviana P, Cioni D, Della Pina C, Sbrana A, Fontanini G, Lencioni R 2010: Thermal ablation of lung tissue: in vivo experimental comparison of microwave and radiofrequency. Cardiovasc Intervent Radiol 33: $818-827$

Date RS, McMahon RF, Siriwardena AK 2005: Radiofrequency ablation of the pancreas. I: Definition of optimal thermal kinitic parameters and the effect of simulated portal venous circulation in a ex-vivo porcine model. J Pancreas (Online) 6: 581-587

Girelli R, Frigerio I, Salvia R, Barbi E, Tinazzi Martini P, Bassi C 2010: Feasibility and safety of radiofrequency ablation for locally advanced pancreatic cancer. Br J Surg 97: 220-225

Hlavsa J, Kala Z, Válek V, Mikulica M, Man M, Procházka V, Kiss I 2008: Radiofrequency ablation (RFA) of pancreatic tumors. Rozhl Chir 87: 462-466

Hlavsa J, Procházka V, Kala Z, Man M, Andrasina T, Č́halová M, Válek P, Crha M, Svobodová I, Urbanová L 2011: Radiofrequency ablation of pancreatic neuroendocrine tumor. Klin Onkol 24: 209-215

Lesser TG, Ritter F, Schlosser H, Boltze C, Hackenbroich C 2011: Effects of radiofrequency ablation on normal lung tissue in a swine model. Acad Radiol 18: 1318-1323

Pollard RE, Long CD, Nelson RW, Hornof WJ, Feldman EC 2001: Percutaneous ultrasonographically guided radiofrequency heat ablation for treatment of primary hyperparathyroidism in dogs. J Am Vet Med Assoc 218: 1106-1011

Spiliotis JD, Datsis AC, Michalopoulos NV, Kekelos SP, Vaxevanidou A, Rogdakis AG, Christopoulou AN 2007: Radiofrequency ablation combined with palliative surgery may prolong survival of patients with advanced cancer of the pancreas. Langebecks Arch Surg 392: 55-60

Tang Z, Wu YL, Fang HQ, Xu J, Mo GQ, Chen XM, Gao SL, Li JT, Liu YB, Wang Y 2008: Treatment of unresectable pancreatic carcinoma by radiofrequency ablation with 'cool-tip needle': report of 18 cases. Zhonghua Yi Xue Za Zhi 88: 391-394 
Vanagas T, Gulbinas A, Pundzius J, Barauskas G 2010: Radiofrequency ablation of liver tumors (I): biological background. Medicina (Kaunas) 46: 13-17

Vanagas T, Gulbinas A, Sadauskiene I, Dambrauskas Z, Pundzius J, Barauskas G 2009: Apoptosis is activated in an early period after radiofrequency ablation of liver tissue. Hepatogastroenterology 56: 1095-1099

Willis WT, Jackman MR, Bizeau ME, Pagliassotti MJ, Hazel JR 2000: Hyperthermia impairs liver mitochondrial function in vitro. Am J Physiol Regul Integr Comp Physiol 278: 1240-1246

Zou YP, Li WM, Zheng F, Li FC, Huang H, Du JD, Liu H 2010: Intraoperative radiofrequency ablation combined with 125 iodine seed implantation for unresectable pancreatic cancer. World J Gastroenterol 16: 5104-5110 
Plate IV

Hlavsa J. et al.: Healing dynamics ... pp. 427-431

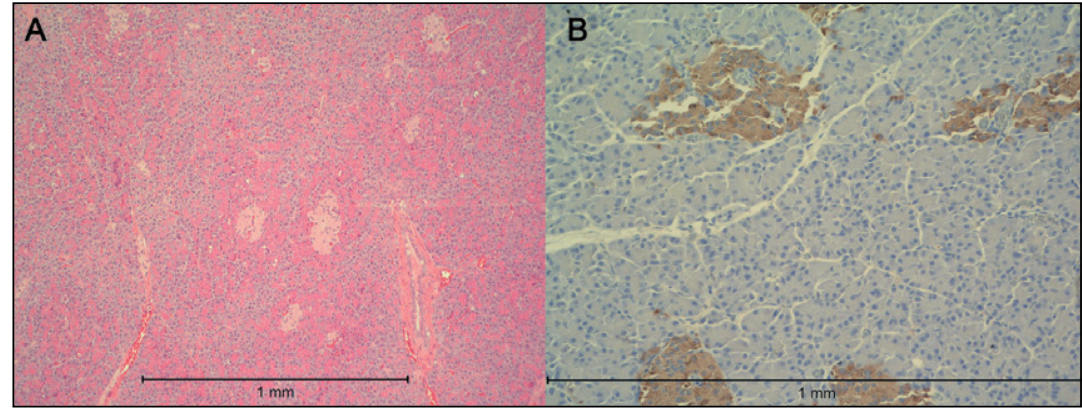

Fig. 1. Histological image of normal porcine pancreas: A - the gland with the dominance of exocrine component (dark pink background) and dispersed endocrine islets (light pink areas), (haematoxylin-eosin stain, $\times 10$ magnification); B - endocrine islets (ocher areas) surrounded by normal porcine pancreatic parenchyma (blue background), (synaptophysin stain, $\times 20$ magnification). Bar - $1 \mathrm{~mm}$.

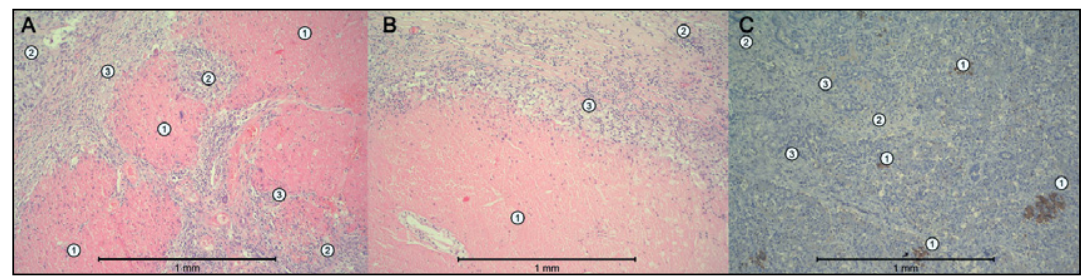

Fig. 2. Histological image of the porcine pancreas 7 days after radiofrequency ablation: A extensive regressive changes (1) consisting of amorphous eosinophilic tissue with surrounding inflammatory-reparative reaction (2) consisted of cellular granular tissue with fibroblasts, capillaries, neutrophils, lymphocytes and macrophages (3), (haematoxylin - eosin stain, $\times 10$ magnification); $\mathrm{B}$ - area of regressive changes (1) consisting of necrotic amorphous eosinophilic masses surrounded by inflammatory-reparative reaction (2) with granular tissue with macrophages phagocytizing necrotic tissue (3), (haematoxylin-eosin stain, $\times 10$ magnification); $\mathrm{C}-$ imunohistochemical image of the porcine pancreas showing disintegrated endocrine islets (1) in the borderline of inflammatory-reparative changes (2) and pancreatic tissue (3), (synaptophysin stain, $\times 10$ magnification). Bar $-1 \mathrm{~mm}$.

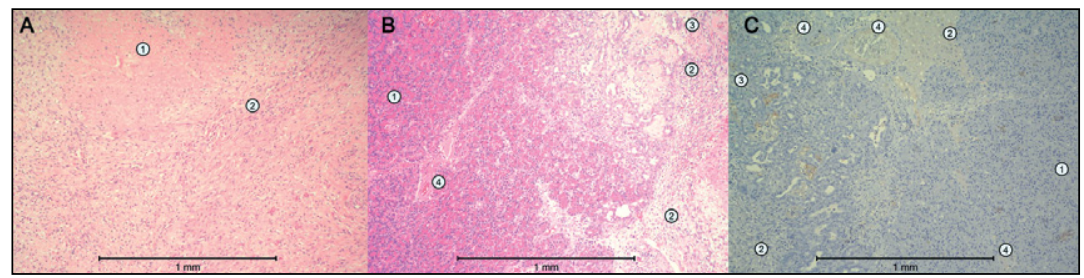

Fig. 3. Histological image of the porcine pancreas 14 days after radiofrequency ablation: A regressive changes (1) with inflammatory-reparative reaction, granular edematous, strongly vascularized tissue with fibroblasts and inflammatory infiltration (2), (haematoxylin- eosin stain, $\times 10$ magnification); B - pancreatic tissue (1) surrounded by inflammatory-reparative changes (2) with residual pancreatic ducts (3), blood vessel (4), (haematoxylin- eosin stain, $\times 10$ magnification); $\mathrm{C}$ - pancreatic parenchyma (1), fibrous granular tissue (2), residual pancreatic ducts (3), blood vessel (4), (synaptophysin stain, $\times 10$ magnification). Bar $-1 \mathrm{~mm}$. 


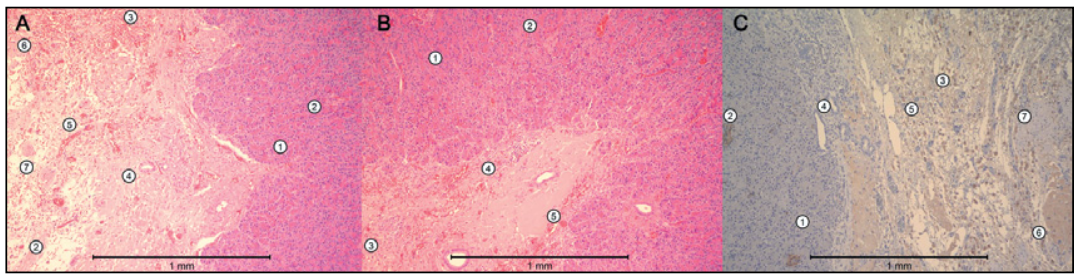

Fig. 4. Histological image of the porcine pancreas 40 days after radiofrequency ablation: A exocrine pancreas (1), endocrine islet (2), inflammatory-reparative changes (3), residual ducts (4), macrophages (5), regressive changes (6), peripheral nerve (7), (haematoxylin- eosin stain, $\times 10$ magnification); B - fibrous granular tissue with inflammatory-reparative changes (3) surrounded by pancreatic parenchyma $(1,2)$, in the border of parenchyma and inflammatoryreparative changes hyalinization is visible (5), residual pancreatic ducts (4), (haematoxylin-eosin stain, $\times 10$ magnification); $\mathrm{C}-$ exocrine pancreas (1), endocrine pancreas (2), inflammatory reparative changes (3), residual ducts (4), macrophages (5), regressive changes (6), peripheral nerve (7), (synaptophysin stain, $\times 10$ magnification). Bar $-1 \mathrm{~mm}$.

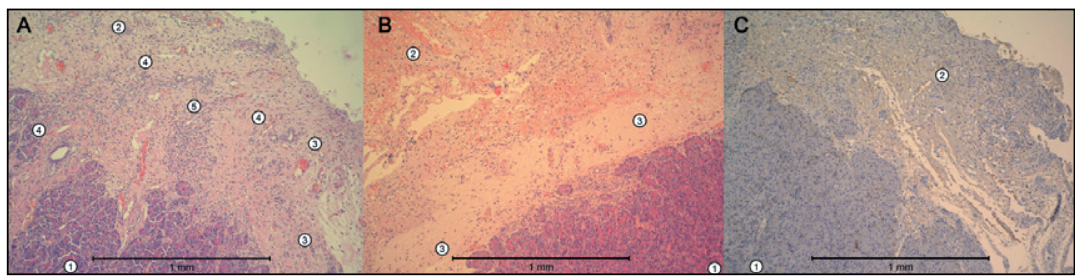

Fig. 5. Histological image of the porcine pancreas 80 days after radiofrequency ablation: A - inflammatory reparative changes (2) consisting of maturing granular tissue, decrease of cellularity and vascularization, with sparse fibrous tissue (3), pancreatic parenchyma (1), residual pancreatic ducts (4), (haematoxylin-eosin stain, 10x magnification); B - pancreatic parenchyma (1), inflammatory-reparative changes (2) maturing to fibrous granular tissue (3), (haematoxylineosin stain, $\times 10$ magnification); $\mathrm{C}$ - pancreatic parenchyma (1), inflammatory-reparative changes (2) with no sign of neuroendocrine cells regeneration, (synaptophysin stain, $\times 10$ magnification). Bar - $1 \mathrm{~mm}$. 